\title{
GRANDJEAN DE MONTIGNY: UM UTÓPICO NO TRÓPICO
}

Marco Antonio Pasqualini de Andrade ${ }^{1}$

\section{Resumo}

Esta comunicação relata um estudo, realizado em 1990, sobre Grandjean de Montigny, o arquiteto francês que integrou a Missão Artística organizada por Lebreton em 1816, que tinha por objetivo fundar uma Academia de Belas Artes no Brasil. A tese principal versa sobre a influência dos arquitetos "utópicos", que atuaram no final do século XVIII na França (Boulée, Ledoux, Lequeu), sobre a produção, idéias e projetos de Montigny. Como instrumento metodológico foi adotado um estudo comparativo visual, englobando desenhos, projetos e fotografias. Observa-se em sua arquitetura o uso de formas simples, geométricas, regulares, simétricas, com uma repetição intensa dos elementos formais empregados. Verifica-se, dessa maneira, que o conceito de "imitação", caro ao neoclassicismo, torna-se matriz de um pensamento utópico, uma arquitetura ideal, irreal, quase impossível, especialmente tendo em vista o contexto cultural, econômico e político de uma nação em devir, no caso o Brasil no período do Império.

Palavras-chave: Arquitetura no Brasil; Neoclassicismo; Missão Francesa

\section{Uma utopia}

Segundo Teixeira Coelho (1987: 7), "a arte de algum modo sempre implica uma utopia, mas as utopias nem sempre implicam a arte". Poderíamos dizer que toda forma de arte busca a sua utopia, o seu não-lugar, e cada manifestação artística possui uma utopia específica, diferenciada, adequada ao espírito de seu tempo.

Tratarei aqui da utopia do Neoclassicismo, que é o que importa no momento. E qual seria ela? A imitação dos clássicos? Creio que não. Imitar seria um modo de se chegar à utopia, que seria a construção de um lugar inexistente, ideal, de perfeição. A imitação, neste caso, é a imagem visível deste ideal, que também poderia ser percebido em sinais menos visíveis e mais simbólicos, como a estruturação matemática, geométrica e pitagórica de sua composição.

Aliás, o que poderia ser menos visível do que um projeto não construído, não tornado real, não tornado visível? Talvez a grande utopia da arquitetura seja alcançada mais plenamente por sua não realização física no espaço.

Contudo, especificamente na arquitetura neoclássica, existe a ambição de tentar realizar outras utopias, como a de criar uma sociedade perfeita, harmônica, pública, monumental. A cidade projetada e seus edifícios imaginados trariam a ilusão de se ter chegado a essa harmonia, a essa monumentalidade, a essa eternidade.

Como mostrarei adiante, tal arquitetura poderia ser especialmente adequada ao frágil primeiro período imperial brasileiro...

\section{Arquitetura neoclássica francesa: revolucionária e imperial}

Para estudarmos a obra de Grandjean de Montigny, devemos antes olhar para dois momentos da arquitetura neoclássica francesa que lhe serviram de referencial: o período da Revolução Francesa (até 1799) e o período do Consulado e Império Napoleônico (terminado em 1815).

1 Doutorando ECA USP; Professor do Departamento de Artes Visuais da Universidade Federal de Uberlândia. 
A época revolucionária, marcada por um idealismo exacerbado, foi um período em que, concretamente, se construiu pouco, pois as agitações políticas e a instabilidade social e econômica não o permitiram. Mas, por outro lado, foi um tempo fertilíssimo de projetos arquitetônicos, dotados do espírito febril revolucionário, no qual se idealizavam templos aos heróis mortos (cemitérios e mausoléus), edifícios públicos (museus, bibliotecas), monumentos comemorativos, por vezes, efêmeros (arcos do triunfo, altares da pátria) e as cidades utópicas, nas quais os ideais de liberdade, igualdade e fraternidade reinariam soberanos.

A forma dada a esses edifícios obedecia, geralmente, a dois princípios básicos: a imitação dos clássicos (principalmente da Grécia democrática e do curto período republicano romano) e a purificação e des-hierarquização dos seus componentes formais (volumes e fachadas). Assim, por um lado, temos o uso de colunas (principalmente a dórica primitiva), arcos plenos, frontões, abóbadas em berço e cúpolas, configuradas em imitações de templos gregos (como o Partenon) ou edifícios romanos (o modelo ideal do Panteão). De outro lado, observamos edifícios simétricos, idênticos nas quatro fachadas (inspirado na Villa Rotonda de Palladio), cuja planta é organizada por círculos e quadrados e cujo volume constrói-se por cubos, esferas, pirâmides e cilindros. A forma perfeita simboliza a sociedade perfeita. Para um mundo utópico, uma arquitetura utópica. E sempre, por ser analtecedora de princípios, monumental e gigantesca.

Deste primeiro período neoclássico francês, época dos estudos de Grandjean, destacam-se dois arquitetos, considerados por Kauffman (1980) revolucionários e precursores da modernidade arquitetônica: Boullée e Ledoux.

Boullée, para quem a arquitetura era o ato de projetar e não o de construir, nasceu em 1728 e morreu em 1799. Construiu pouca coisa, sendo sua obra mais conhecida o Hôtel de Brunoy, de 1772. Antes de se tornar arquiteto, estudou pintura e, posteriormente, com Blondel, conhecido professor e teórico do século XVIII. Foi admitido na segunda classe da Academia de Arquitetura em 1762, passando à primeira, no lugar de Souflout, em 1786. Permaneceu lá, como professor, até seu fechamento em 1793. De 1795 até sua morte foi professor do Institut de France, órgão que reunia as ciências, letras e artes, substituto das antigas academias. Sua obra é conhecida através de seus desenhos e de um manuscrito, L'Architecture, conservados na Bibliotèque Nationale de Paris. Seus projetos passam por várias categorias, quase todas de caráter público: portas da cidade, cenotáfios, museus, igrejas, teatros, arcos do triunfo, bibliotecas e palácios de órgãos públicos (governo municipal, assembléia, justiça). Neles, percebe-se o uso de cones, pirâmides, esferas, quase que em estado puro, acompanhados muitas vezes por colunatas e pórticos de inspiração grecoromana. Sua preocupação com a luz e a sua ausência (fazia desenhos representando os edifícios ao dia e à noite) e o destino de seus edifícios a grandes multidões se evidencia em muitas perspectivas. A forma simbólica de seus edifícios é patente. A monumentalidade se dá pelo uso de formas simples em dimensões colossais, pela unidade do conjunto e pela ausência de detalhes decorativos.

Ledoux nasceu em 1736. Estudou gravura, especializando-se em cenas de batalhas. Foi admitido na Academia de Arquitetura em 1773, como membro da segunda classe, nunca tendo sido aceito na primeira. Estudou também com Blondel. Ao contrário de Boullée, projetou e construiu muitos edifícios na década de 1770 e início da de 1780 , cessando a procura de seus projetos no período revolucionário. Foi perseguido, preso, e escapou por pouco da guilhotina, por ter sido arquiteto do rei. Dedicou-se então a publicar um livro por conta própria, que reunia seus projetos de 1768 a 1789, que recebeu o título 
de L'Architecture considérée sous lê raport de l'Art, dês Mouers et la Législation, em 1804. Faleceu em 1806. Em seu livro estão reunidos vários projetos não realizados, inclusive o de uma cidade ideal, a ser construída nas salinas de Chaux, que se configura em planta como uma forma ovalada, na qual estão dispostos os vários edifícios públicos. Menos radical que Boullée, utiliza os mesmos conceitos de formas básicas, mas articuladas de maneira mais complexa, nas quais se notam contrastes de dimensões e formas, ausentes de hierarquia, massas volumétricas que se interpenetram e se sobrepõem. Suas partes são tão independentes que às vezes parecem fragmentadas, mas existe a mesma idéia de monumentalidade, que vem enfatizada em vários projetos pela existência de uma base ou podium sob o prédio principal.

Já o segundo período do neoclassicismo francês, que corresponde à época do Império, caracteriza-se por utilizar a arquitetura para glorificar a imagem do imperador, Napoleão Bonaparte. Ao lado dos projetos públicos já desenvolvidos anteriormente, são elaborados projetos de monumentos (obeliscos, arcos do triunfo, chafarizes), praças, parques e, principalmente, palácios. O purismo das formas revolucionárias cede lugar a uma arquitetura menos radical, na qual a função importa mais do que o símbolo. A decoração e o detalhe ganham maior destaque, em detrimento das massas volumétricas, o que acrescenta ao caráter monumental um aspecto suntuoso.

Dois arquitetos resumem o período, exatamente aqueles com quem Grandjean de Montigny realizou seus estudos: Charles Percier e Fontaine. Os dois obtiveram o Prix de Rome (em 1783 e 1785, respectivamente) e, quando voltaram a Paris, em 1791, iniciam um trabalho conjunto. Lecionam aulas particularmente e, mais tarde, também no Institut de France. Percier, desenho e arquitetura e Fontaine, perspectiva. Percier, mais ligado à Revolução, integrou a Commune dês Arts, fazendo parte da Comissão de Monumentos. No período do Consulado, e depois também no Império, os dois tornam-se arquitetos de Napoleão, realizando reformas no interior e exterior de palácios e construindo monumentos, chafarizes e arcos do triunfo (seu projeto mais famoso é o Carroussel em frente ao Louvre). Utilizam a simetria a partir de um eixo central, mas estabelecendo hierarquias de volumes e fachadas. Semicírculos e retângulos são formas que comparecem freqüentemente em seus projetos. A decoração interna de seus edifícios é policromada, inspirada pelas recém descobertas casas das escavações de Pompéia.

Quando Napoleão é destituído, em 1815, a arquitetura novamente mudará de rumo, com a chegada dos ares românticos que distanciam-se da monumentalidade neoclássica.

\section{Grandjean de Montigny}

Auguste Henri Victor Grandjean de Montigny nasceu em Paris, França em 15 de junho de 1776. Fez seus estudos iniciais na École d'Architecture de Paris, onde tem aulas com Delannoy, Percier e Fontaine. Após três provas preliminares, em 1799, é admitido ao concurso do Grand Prix de Rome, o qual vence em primeiro lugar juntamente com Louis Gasse, e no qual apresenta um projeto de um Eliseu ou Cemitério público.

Este projeto se destaca pela configuração de sua planta, na qual são utilizadas figuras geométricas simples (círculo, quadrado) e a singular simetria de todas as suas fachadas, idênticas. É possível compará-lo com alguns projetos de Boullée e Ledoux, que seguem a mesma configuração. Em sua fachada nota-se o uso de arcadas, colunatas que formam uma loggia ou passeio público, e também um pequeno pórtico de inspiração grega. Através do corte percebe-se a presença de abóbodas romanas em berço e rotundas sobrepostas. A repetição e sobreposição de tais elementos formais são características do 
neoclassicismo e estarão sempre presentes em futuros projetos do arquiteto, constituindo um esquema que se tornará cada vez mais inflexível. A inclusão de uma arborização rigorosa de formato cônico (pinheiros e ciprestes) marca a verticalidade e reforça o caráter monumental do edifício.

Nestes anos de estudo recebe vários prêmios em concursos, como o do embelezamento dos Champs Elisées, no qual participa conjuntamente com Famin, Debret e Bury.

Em 1801 chega a Roma, onde permanece até 1805. Neste período participa do projeto de restauração da Villa Médici, na qual seria instalada a sede local da Academia Francesa. Realiza várias viagens pela Itália, quando inicia, junto com Famin, uma publicação de desenhos de monumentos antigos. Seu trabalho de conclusão é o projeto de restauração do túmulo de Cecília Matella, na Via Appia.

Em seguida, volta a Paris e, logo após, muda-se para a Vestfália, pequeno reino dirigido por Jerônimo Bonaparte, irmão do imperador, onde desenvolve e executa vários projetos, entre eles um Arco do Trunfo, o portão para as cavalariças reais, fontes e chafarizes, o plano para o Parque Cathrinental e a reforma do Palais dês Etats de Kassel (atual sede da exposição Documenta). Permanece lá até 1913 (quando o reino foi desfeito), retornando a Paris, onde publica o restante dos fascículos sobre a Arquitetura Toscana e também um outro volume sobre a Arquitetura Tumular da Itália.

Quando cai o império napoleônico, em 1915, sua posição como antigo arquiteto da corte o coloca em situação politicamente delicada, e então Grandjean recebe dois convites para trabalhar fora da França: um vindo do Czar Alexandre I da Rússia e outro da parte de LeBreton, que na época organizava uma Missão Artística, encomendada pelo Regente Português, D. João VI, a ser enviada ao Brasil. Aceitou a segunda opção e desembarcou na América em 26 de março de 1816, juntamente com Debret e a família Taunay, com a tarefa de projetar o edifício da Academia de Belas Artes (que só seria terminada dez anos depois) e formar novos arquitetos.

Nestes primeiros anos no Brasil participa, junto a Debret, da realização de cenários para comemorações públicas: em 1817, quando da chegada de D. Maria Leopoldina (Arco Romano, Triunfo Romano); em 1818, para a aclamação de D. João VI (Arco Trunfal, Templo de Minerva, Obelisco) e para o aniversário e casamento de D. Pedro (um Estádio no Campo de Santana).

Conhecemos estes projetos por gravuras, desenhos ou descrições, sendo sua identificação apenas parcial. É de se destacar o pequeno templo circular, cercado por uma colunata coríntia, encimado por uma pequena cúpola, tendo em seu ápice uma estátua. Tanto o projeto, como o desenho em si, atribuído a Grandjean, denotam um refinamento e delicadeza quase românticos (o que se percebe também nas aquarelas de Debret).

Em 1820 conclui a construção de seu projeto para a primeira Praça de Comércio (atual Casa França Brasil), com a qual é condecorado com a vênera de Cavaleiro da Ordem de Cristo por D. João VI.

Este é o primeiro edifício de Montigny projetado, executado e concluído no Rio de Janeiro. Não se trata de uma obra de porte, mas nele o arquiteto coloca muito de suas pretensões de monumentalidade. O Projeto é simétrico pelo eixo central, constituindo sua planta em um retângulo cortado em cruz. A fachada (que não foi executada exatamente como no projeto) constituía-se em uma seqüência de arcadas centralizada por um óculo semicircular e um frontão triangular. Nos dois extremos superiores estátuas representariam a Europa e a América (apenas a primeira foi executada, mas nunca foi colocada em seu 
lugar, permancendo no vão da escada da Academia). Na entrada uma pequena escadaria com quatro outras estátuas que deveriam representar o Comércio, a Navegação, a Agricultura e a Indústria. A execução modificou as janelas, tornando-as ovaladas (constituídas de dois arcos plenos ligados por um segmento de reta). A ausência das estátuas mostrou-se prejudicial à monumentalidade pretendida, o que, por outro lado, acentua a aparente simplicidade do projeto, ou melhor, a sua pureza formal, que encontra ecos em projetos de Ledoux, nos quais pode-se notar solução semelhante. Em uma vista aérea percebe-se a riqueza do jogo de telhados, frontões e aberturas utilizados para a resolução do espaço interno, certamente monumental. Observando a perspectiva interna desenhada por Montigny pode-se ter idéia deste espaço, rodeado de colunas caneladas revestidas de madeira que sustentam a cornija onde pousam as abóbodas e a cúpola. Neste desenho percebe-se o uso de um recurso gráfico que acentua a monumentalidade e impacto do projeto: a diminuição de escala das figuras humanas, o que as torna insignificantes no contexto da grande espacialidade proposta. Este recurso é também utilizado por Boullée em algumas perspectivas.

Ao mesmo tempo, enquanto a Academia não é inaugurada, dá aulas particulares e projeta algumas residências, entre as quais a mansão do Comendador Oliveira Barbosa na Rua do Passeio Público e a do Sr. Dias em Catumby.

Em 1827 apresenta o projeto de reestruturação do Campo de Santana, no qual cria uma praça, passeios públicos, edifícios e monumentos, um arco do triunfo, uma estátua eqüestre e a igreja de S. Pedro de Alcântara. A Praça da Aclamação projetada pretende regularizar a imensa praça, que exibe originalmente uma forma irregular. Retoma aqui idéias desenvolvidas para a ligação do Louvre às Tulheries, com suas arcadas e monumentos. $\mathrm{O}$ "passeio" pode ser visto como uma reinterpretação das loggias italianas.

No ano seguinte há notícias de que pretendia rifar sua residência na Gávea, também projetada por ele, mas abandona a idéia, permanecendo nela até sua morte.

Mário H. G. Torres escreve um interessante texto sobre esta casa, na qual aborda a origem da planta, da coluna dórica primitiva, do terraço sobre arcadas e outras questões. A respeito da planta, suponho que não haja dúvidas que seu modelo era um partido comum de muitas casas francesas, e inclusive já havia sido usada por Montigny em um Cassino na Vestfália, que foi adaptado e modificado pelo arquiteto. Talvez a grande dúvida seja se teria havido alguma intenção de regionalismo ou abrasileiramento neste edifício, com o uso das varandas circundadas pelas colunatas. Torres compara tal iniciativa a fazendas próximas ao Rio de Janeiro, que poderiam ter sido vistas, visitadas e tomadas como referência para o projeto. Porém, enquanto caso isolado, tal "nacionalização" pode ser questionada. Observando outros projetos de Grandjean de Montigny ainda da fase européia, especialmente o de um teatro em Nápoles, verifica-se que a solução já havia sido experimentada antes, a mesma dupla colunata sobreposta circundando a fachada, porém neste em forma semicircular. Ainda pode-se encontrar esquema semelhante, salvaguardando as inúmeras diferenças, em obras de Palladio (que era uma fonte importante de inspiração aos neoclássicos). Talvez, percebendo a possibilidade de sua adequação ao clima brasileiro, o arquiteto tenha lançado mão do recurso, mas com a persistência de uma postura formal advinda da academia francesa. A singular arcada, que serve de base para a casa, da mesma forma, encontra antecedentes em propostas de Ledoux, ou a própria Villa Médici restaurada por Montigny em Roma.

Esta é a época de constantes choques com o diretor da Academia, Henrique José da Silva, que ficará no cargo até sua morte, em 1934. Durante esses anos projeta o teatro São 
Francisco de Paula, realiza os festejos da chegada de D. Amélia (segunda imperatriz do Brasil), além da segunda Praça do Comércio e do Mercado da Candelária, na Praia do Peixe.

Nos anos seguintes, com a situação mais estável da Academia, dedica-se à tentativa de abrir uma rua e construir uma pracinha em frente ao edifício, para criar uma perspectiva que o valorize. Montigny possuía a necessária compreensão de que não basta que o edifício seja, em si, monumental, mas que todo contexto ao seu redor o auxilie nesta tarefa, pois é este conjunto que constitui o mais importante, que é a imagem da cidade.

Em 1838 termina o restauro do Colégio D. Pedro II, o qual recebe críticas negativas públicas em jornais da época.

Em 1844 Grandjean faz um projeto para um chafariz-monumento à chegada da Imperatriz Tereza Cristina, na Praça Municipal, assim como sua readaptação. Dois anos depois projeta os chafarizes da Benfica e da Rua São Clemente. Outro chafariz será construído no Largo do Rossio Pequeno, que demandou várias solicitações por parte da Academia para a observância de seus riscos originais.

Seus chafarizes, de maneira geral, seguem um esquema semelhante: uma bacia circular maior em baixo, seguida por um cilindro vertical de onde saem cabeças de leão que jorram água por suas bocas. Acima do cilindro é colocado um fechamento decorativo. Este mesmo modelo pode ser encontrado, quase sem modificações, em um projeto de Percier e Fontaine. A originalidade de Montigny comparece no chafariz da Praça Onze, no qual superpõe três bacias de tamanhos diferentes (o que não foi seguido na sua execução) e no da Praça do Peixe (localizado internamente ao Mercado da Candelária), em que ao invés de um cilindro coloca pequenas colunas que sustentam golfinhos e um cubo com quatro esferas, coroado por uma pirâmide alongada. O chafariz da Benfica também propõe um outro esquema, quadrado e simétrico, no qual instala um pórtico grego em cada fachada. Nestes exemplos nota-se um uso intensivo de formas geométricas simples e simétricas, incluindo esferas e pirâmides, que são freqüentes nos arquitetos da época revolucionária, especialmente Boullée.

Nessa época desenvolve vários projetos, nunca construídos, para um Palácio Imperial, um Palácio do Senado e uma Biblioteca Imperial, com a qual é agraciado com a Ordem da Rosa. Há uma grande semelhança entre o primeiro projeto para a Academia de Belas Artes e o segundo projeto para o Palácio Imperial. Embora de escalas diferentes, tanto o desenho da fachada com um arco sobreposto por um pórtico hexástilo, os três andares e a composição com dois outros edifícios laterais são extremamente parecidos. Esta repetição de soluções e formas é um dos princípios da proposta de imitação neoclássica, que não pretendia uma originalidade, mas uma busca de perfeição e o ideal de encontrar o melhor arranjo para um dado esquema e pesquisa formal.

Envolve-se também, nestes últimos anos, com a concepção de vários projetos urbanos, propondo criar eixos monumentais ligando a Praça do Rossio ao novos palácios projetados. Estas ligações fazem-se através de praças em semicírculo, forma usada por Montigny na Vestfália e no seu projeto de embelezamento dos Champs Elisées de Paris. Tal uso é comum também em obras de Percier e Fontaine. Nota-se a preocupação de desenvolver a circulação urbana, modernizando a cidade do Rio de Janeiro através da construção de grandes eixos, como os que faria Hausmann em Paris.

Em $1^{\circ}$. de março de 1850, aos 74 anos, falece de um resfriado adquirido durante o carnaval e é enterrado no Convento de Santo Antonio. 


\section{Um utópico no trópico}

Embora pertencendo a uma geração que serviu essencialmente às vontades monumentais de imperadores, Grandjean de Montigny manteve, em parte de seus projetos, as formas puras que tanto caracterizaram os arquitetos da época da Revolução Francesa, embora nunca tendo sido tão ousado como estes. Nesse sentido, o fato de privilegiar a cidade, o ambiente público, o "passeio", faz com que pensemos se, na realidade, apesar de cumprir seu papel de arquiteto oficial, não haveria uma intenção de construir a sua cidade ideal. O período em que atuou no Brasil foi bastante atribulado e não propício aos gastos públicos, devido às constantes crises por que passava o Império. Este, que solicitava seus projetos, mas raramente os executava, contribuiu para uma orientação em favor do aspecto utópico de seus projetos. É possível que Grandjean de Montigny interessava-se mais pelo significado urbano de seus edifícios do que propriamente com sua função e uso. No país onde tudo estava por se fazer, a atuação pioneira do grupo francês poderia buscar mais do que um refúgio à situação política européia. Com as dificuldades de efetivar o projeto neoclássico no Brasil, contudo, a situação complexa exigira uma escolha. Debret retornou à França. Montigny resolveu permanecer. Por que? Talvez justamente por tal alternativa possibilitar sua pesquisa utópica, ideal, sem efetivos compromissos com o governo imperial, que lhe pagava para conceber projetos que nunca seriam realizados. Além disso, o grande uso da repetição concede uma notável unidade entre edifícios diferentes, e um caráter de infinitamente grande, infinitamente extenso, enfim, monumental. $\mathrm{E}$ isto torna o edifício facilmente compreensível, pois se vendo uma parte, se vê o todo. O que se procura é uma "ordem", conceito tão caro aos antigos gregos. Mais do que transformar a cidade em um espetáculo multivariado, o arquiteto tenta fazê-la compreensível colocando referências semelhantes que a ordenem e unifiquem. Grandjean de Montigny era um arquiteto que tinha monumentais idéias, e uma vontade de colocá-las em prática, mas sabendo da dificuldade em realizá-las. Um utópico no trópico. Um utópico em essência ou, ao menos, em circunstância.

Alguns, como Bruno Zevi, consideram os projetos apenas sonhos, vislumbres da arquitetura verdadeira que é aquela construída. Outros consideram as construções realizações eternamente imperfeitas e limitadas da verdadeira utopia dos arquitetos: aquela presente no projeto.

\section{Referências Bibliográficas:}

BARDI, Pietro Maria. A arquitetura brasileira. In: BENEVOLO, Leonardo. Introdução à Arquitetura. São Paulo: Mestre Jou, 1972.

História da Arte Brasileira. São Paulo: Melhoramentos, 1975.

BRUAND, Yves. A fundação do ensino acadêmico e o neoclassicismo no Brasil: a ação de Marcos e Zeferino Ferrez, escultores franceses no Rio de Janeiro. RIEGB. V. 311, p. 101.

COELHO, Teixeira. Arte e Utopia. São Paulo: Brasiliense, 1987.

CORREA Filho, V. Grandjean de Montigny. Mensário do Jornal do Comércio. Rio de Janeiro, tomo 24, v.1, 1943, p.75.

FREITAS, B. Ribeiro de. Grandjean e a arquitetura brasileira. Brazil Artístico Nova Fase. Rio de Janeiro, ano I, n.1, p. 245. 
HAUTECOEUR, Louis. Histoire de L'Architecture Classique em France. Paris: Editions A. et J. Picard, 1953, tomo V.

KAUFMANN, Emil. Tres Arquitectos Revolucionarios: Boullée, Ledoux, Lequeu. Barcelona: Gustavo Gili, 1980.

MORALES DE LOS RIOS Filho, Adolfo. Grandjean de Montigny e a Evolução da Arte Brasileira. Rio de Janeiro: A Noite, 1941.

MELLO Jr, Donato. Bicentenário do nascimento de Grandjean de Montigny. Boletim do Conselho Federal de Cultura. Rio de Janeiro, n. 34, jan./fev./mar. 1979, p. 24.

NORONHA SANTOS, Fontes e chafarizes do Rio de Janeiro. Arquitetura Oficial II. São Paulo: FAU USP / MEC-IPHAN, 1978.

REIS Filho, Nestor Goulart. Quadro da Arquitetura no Brasil. São Paulo: Perspectiva, 1970.

SANTOS, Paulo F. Quatro Séculos de Arquitetura. Rio de Janeiro: Fundação Ed. R. Pimentel, 1977.

STAROBINSKY, Jean. 1789: Os Emblemas da Razãa. São Paulo: Companhia das Letras, 1988.

TAUNAY, Afonso d'Escragnole. A Missão Artística de 1816. Rio de Janeiro: Diretoria do IPHAN, 1956.

UMA CIDADE EM QUESTÃO I: Grandjean de Montigny e o Rio de Janeiro. Rio de Janeiro: PUC, 1979. (catálogo de exposição)

VIANA, Araújo. O estilo clássico na arquitetura do Rio de Janeiro. Renascença. Rio de Janeiro, ano 3, fev. 1906, n. 24, p. 45.

ZEVI, Bruno. Architectura in Nuce: uma definição de arquitetura. São Paulo: Martins Fontes, 1986. 